\title{
Benzidine Containing Dye
}

National Cancer Institute

\section{Source}

National Cancer Institute. Benzidine Containing Dye. NCI Thesaurus. Code C45406.

A dye consisting of a diazotized benzidine nucleus that can have a wide variety of colors depending on the chemical groups attached at the diazo linkages. Benzidine based dyes are mainly used to color textiles, leather and paper but are also found in the rubber, plastic, soap, hair dye and petroleum industries. All benzidine containing dyes are considered human carcinogens based on the fact that they are metabolized in vivo to form free benzidine. ( $\mathrm{NCl05)}$ 